\title{
Criminal Law and Public Health Practice: Are the Canadian HIV Disclosure Laws an Effective HIV Prevention Strategy?
}

\author{
Patrick O’Byrne
}

Published online: 11 June 2011

(C) The Author(s) 2011. This article is published with open access at Springerlink.com

\begin{abstract}
Over the last few years, the number of people living with HIV who have been convicted for not disclosing their HIV status to sexual partners in Canada has been steadily increasing. Whilst these laws are criminal in nature, and not public health-based, it is important to examine their effect on public health HIV prevention efforts. To undertake such an analysis, the impact fraction model was used to structure and examine the extant literature about HIV transmission, HIV status awareness and HIV testing practices. The findings of this analysis indicate that although these laws might prevent HIV transmission in a few isolated cases, it is unlikely that they would influence overall population-level rates of HIV transmission. Some evidence even suggests that these laws could exacerbate HIV transmission.
\end{abstract}

Keywords Canada $\cdot$ Health Policy $\cdot$ HIV Impact Fraction Model $\cdot$ Law Public Health

\section{Introduction}

Whilst the last few years have witnessed many changes in the health care practices that relate to HIV management, care and quality-of-life outcomes for people living with HIV and AIDS (PHA), in Canada, significant alterations have also occurred regarding the legal context surrounding the disclosure of a person's HIV-positive serological status (henceforth referred to as serostatus disclosure). This

\section{P. O’Byrne $(\square)$}

Faculty of Health Sciences, School of Nursing,

University of Ottawa,

451 Smyth Road,

Ottawa, ON, Canada K1H 8M5

e-mail: pjobyrne@uottawa.ca change, specifically in the Canadian context, has included an increase in the frequency of charges being brought against PHAs; by the end of 2009, there had been 96 prosecutions related to serostatus non-disclosure across Canada, with $>70$ of these cases having resulted in conviction, and more than 35 having been between 2006 and 2009 (Myhkalovskiy et al. 2010). In reaction to this increasing practice of criminally charging PHAs for not disclosing their serostatus, many advocacy/legal groups that work with and for PHAs have denounced this trend (see Cameron 2009; Symington 2009). Some researchers, moreover, have begun to examine PHA's degree of awareness about HIV criminal law and the effects that this law might have on behaviour (Adam et al. 2008; Burris et al. 2007; Galletly and Pinkerton 2006, 2008; Lazzarini et al. 2002). These findings are presented below.

Notwithstanding this research base what continues to be underrepresented in the current debates is empirically informed discussions/examinations of the criminal prosecution of serostatus non-disclosure from a public health perspective. Indeed, the research literature to date focuses more on ethical and legal issues than public health, which is surprising and disconcerting because, first, HIV is a public health issue and, second, the current legal context in Canada may unwittingly undermine HIV prevention efforts across the country; other countries may be experiencing similar legal trends, but have not yet been examined either. To address this gap, this paper summarizes the extant literature about HIV transmission and disclosure law (the latter item specifically in the Canadian context) and then structures this work from a public health/HIV prevention perspective using the impact fraction model. The questions posed as part of this examination are thus, to what extent and effect do serostatus disclosure laws, which have a criminal and not public health focus, function as HIV prevention initiatives? Do criminal laws that 
relate to serostatus non-disclosure affect public health efforts, and if so, in what way? To date, no discussions have specifically addressed questions relating to the relationship between the criminalization of serostatus non-disclosure and public health.

\section{Conceptual Framework: The Impact Fraction Model}

To undertake this analysis, the impact fraction model was be used. As its name indicates, this model highlights that the impact of a health intervention depends on (1) the fractional importance of a target group (i.e. how much does the target population contribute to the overall health status of a population?); (2) the efficacy of the proposed intervention (i.e. how well does it work?); and (3) the coverage that can be achieved when a specific intervention is implemented (i.e. how many individuals actually use or are involved in the intervention?; Dooley and Thrun 2008; Aral et al. 2007). According to the impact fraction model, whilst each of the foregoing items affects an intervention's impact, it is the combination of these factors that ultimately determines an intervention's overall effect on health. As a formula:

$$
\begin{aligned}
{[\text { Impact }]=} & {[\text { Importance of Group }] \times[\text { Intervention Efficacy }] } \\
& \times[\text { Intervention Coverage }]
\end{aligned}
$$

As this relates to HIV, the most profound prevention effects would therefore occur if highly efficacious interventions were implemented with high uptake among individuals who are most responsible for transmission. In this context, to determine whether the criminal enforcement of serostatus disclosure would have a profound public health/prevention impact, the literature on HIV transmission and disclosure law will be examined using the impact fraction model.

\section{Background Information: HIV Transmission and HIV Criminal Law}

\section{HIV Transmission in Canada}

In Canada, the overall incidence of HIV has remained relatively stable since 2001: approximately 2,300 to 4,300 new cases occurring annually, with roughly $80 \%(1,840$ 3,440 ) of these cases occurring by means of sexual contact. Although this figure has not fluctuated greatly since 2001, the absolute number of PHAs has continued to grow during this time. At present, there are approximately 65,000 (range of 54,000-76,000) PHAs in Canada, which equates to a prevalence of $0.4 \%$ (PHAC 2009). Compounding this situation is that PHAC estimates only $74 \%$ (48,100; range, $39,960-56,240)$ of PHAs in Canada are aware of their serostatus; the remaining $26 \%(16,900$; range, 14,040 19,760 ) do not know that they are living with HIV (PHAC 2009). Of particular importance, research by Marks et al. (2005) highlights that this latter group might be responsible for $54-70 \%$ of all new cases of HIV.

By the numbers, this means that in Canada, 26\% $(16,900$; range, $14,040-19,760)$ of the entire prevalent group $(65,000$; range, $54,000-76,000)$ cause between $994-$ 1,288 (54-70\%, respectively, of the lower number of 1,840 incident cases) and 1,858-2,408 (54-70\%, respectively, of the higher number of 3,440 incident cases) of the annual incident cases of HIV in Canada each year (PHAC 2009). As rates, one can suggest an HIV transmission rate (by means of sexual contact) that ranges between $5.88-7.62 \%$ (944-1,288 cases divided by 16,900 , the $26 \%$ of PHAs unaware of serostatus) and $10.99-14.25 \%(1,858-2,408$ cases divided by 16,900 , the $26 \%$ of PHAs unaware of serostatus). When these figures are generated for the $74 \%$ $(48,100$; range, 39,960-56,240) of PHAs aware of their serostatus, a markedly different set of rates emerges: HIV transmission among PHAs aware of their serostatus ranges between $1.15-1.76 \%(552-847$ divided by 48,100$)$ and $2.15-3.29 \%(1,032-1,583$ divided by 48,100$)$. These numbers thus reveal that there are significantly higher rates of HIV transmission among people who are unaware of their serostatus than among individuals who are aware that they are living with HIV. See Table 1 for a summary of these figures.

Individuals who are unaware of their serostatus are not, however, a homogenous group. There is a distinction between individuals who have an acute infection (who, in many situations, cannot be diagnosed with HIV) and individuals who do not undergo HIV testing. Research on the role of acute HIV infection in the sexual transmission of HIV indicates that the heightened concentration of HIV in genital fluids during this time period may be relatively small or quite significant; mathematical modelling predicts that anywhere between $1 \%$ and $82 \%$ of new HIV infections are the result of a sexual partner who is in the acute period of HIV infection. The variability of these numbers relates to an array of factors: the stage of the HIV epidemic (i.e. Is HIV a new or established infection within a given population?); the time between HIV acquisition and diagnosis (i.e. What is the proportion of delayed HIV diagnoses?); the sexual dynamics of specific groups (e.g. What are the rates of sexual concurrency and new partnerships?); and the rates of HIV testing among members of a specific population of interest (i.e. How many people in a group are unaware of their serostatus/ how frequently do individuals undergo HIV testing?). 
Table 1 HIV transmission in Canada

\begin{tabular}{|c|c|c|c|c|c|}
\hline Item & & \multicolumn{4}{|l|}{ Numbers } \\
\hline Prevalence & \multicolumn{4}{|c|}{$65,000(54,000-76,000)$} & \\
\hline \multirow[t]{2}{*}{ Serostatus awareness } & \multicolumn{2}{|c|}{$26 \%$ unaware } & \multicolumn{3}{|c|}{$74 \%$ aware } \\
\hline & \multicolumn{2}{|c|}{$16,900(14,040-19,760)$} & \multicolumn{3}{|c|}{$48,100(39,960-56,240)$} \\
\hline \multirow[t]{2}{*}{ Incidence } & \multicolumn{4}{|c|}{$2,300-4,300$} & \\
\hline & \multicolumn{4}{|c|}{$80 \%$ related to sexual transmission $=1,840-3,440$ cases } & \\
\hline \multirow[t]{9}{*}{$\begin{array}{l}\text { Incidence and serostatus } \\
\text { awareness }\end{array}$} & \multicolumn{2}{|c|}{$\begin{array}{l}26 \% \text { unaware of serostatus involved in } 54-70 \% \\
\text { of sexually transmitted HIV }\end{array}$} & \multicolumn{3}{|c|}{$\begin{array}{l}74 \% \text { aware of serostatus involved in } 30-46 \% \\
\text { of sexually transmitted HIV }\end{array}$} \\
\hline & 1,840 & 3,440 & & 1,840 & 3,440 \\
\hline & $54 \%$ & 1,858 & $30 \%$ & 552 & 1,032 \\
\hline & $\begin{array}{l}70 \% \\
\frac{994-1,288}{16,900^{\mathrm{a}}}\end{array}$ & $\begin{array}{l}2,408 \\
\frac{1,858-2,408}{16,900^{\mathrm{a}}}\end{array}$ & $\begin{array}{l}46 \% \\
\frac{552-847}{48,100^{\mathrm{a}}}\end{array}$ & $\begin{array}{l}847 \\
\text { to }\end{array}$ & $\begin{array}{l}1,583 \\
\frac{1,032-1,583}{48,100^{\mathrm{a}}}\end{array}$ \\
\hline & \multicolumn{2}{|c|}{$=(5.88-7.62 \%)$ to $(10.99-14.25 \%)$} & \multicolumn{3}{|c|}{$=(1.15-1.76 \%)$ to $(2.15-3.29 \%)$} \\
\hline & \multicolumn{2}{|c|}{$\begin{array}{l}\text { Therefore, the rate of sexually transmitted HIV for people } \\
\text { unaware of serostatus is between } 5.88 \% \text { and } 14.25 \%\end{array}$} & \multicolumn{3}{|c|}{$\begin{array}{l}\text { Therefore, the rate of sexually transmitted HIV for people } \\
\text { aware of serostatus is between } 1.15 \% \text { and } 3.29 \%\end{array}$} \\
\hline & $\frac{994-1,288}{26 \%}$ & $\frac{1,858-2,408}{26 \%}$ & $\frac{552-847}{74 \%}$ & to & $\frac{1,032-1,583}{74 \%}$ \\
\hline & \multicolumn{2}{|c|}{$=(38.23-49.54)$ to $(71.46-92.62)$} & \multicolumn{3}{|c|}{$=(7.46-11.45)$ to $(13.95-21.39)$} \\
\hline & \multicolumn{2}{|c|}{$\begin{array}{l}\text { Therefore, there are between } 38 \text { and } 93 \text { incident cases } \\
\text { of HIV per } 1 \% \text { of people unaware of serostatus }\end{array}$} & \multicolumn{3}{|c|}{$\begin{array}{l}\text { Therefore, there are between } 7 \text { and } 21 \text { incident cases } \\
\text { of HIV per } 1 \% \text { of people aware of serostatus }\end{array}$} \\
\hline
\end{tabular}

${ }^{\mathrm{a}}$ The average figure was used here intentionally to avoid producing additional ranges

As noted above, in the Canadian context, the proportion of individuals unaware of their serostatus is estimated to be $26 \%$ (Marks et al. 2005). The percentage of this group that is within the acute HIV infection period, however, is likely small: Research identifies that in Canada, upwards of $62 \%$ of HIV diagnoses are delayed, meaning that nearly two thirds of people in Canada receive their initial HIV diagnosis within 12 months of being diagnosed with AIDS (Hall et al. 2009). Consequently, in the absence of any research data that precisely focus on the role of acute HIV infection in HIV transmission in Canada, it appears as though the available and related information which exists suggests that whilst acute HIV infection may correspond with an increased degree of HIV transmissibility, the significance of this stage of infection cannot be overstated in the Canadian context because of the large number of people who receive delayed HIV diagnoses. In other words, acute HIV infection likely plays a role, but the available research suggests that this role is likely small.

\section{HIV Criminal Law}

In Canada, there are no formally enacted statutes which criminalize any aspect of HIV transmission or serostatus disclosure. There are, however, legal precedents, the most notable of which is the Supreme Court of Canada's $R$. v. Cuerrier case from 1998, in which a man who transmitted HIV during unprotected vaginal sex was convicted of aggravated assault. In this ruling, the Supreme Court established that people living with HIV must disclose their serostatus prior to the onset of any sexual contact that poses a "significant risk" for HIV transmission, provided that the awareness of this information would have changed whether or not sexual contact would have occurred (CHALN 2004). The court insisted that failure to disclose one's serostatus invalidates consent, if and when the disclosure of this information would have impacted on a person's decision to give consent. As part of this, the court also ruled that HIV transmission is an act that inflicts irreversible harm onto another person. This ruling thus established that the issue under Canadian law is one of serostatus disclosure, not HIV transmission or intent to transmit HIV (CHALN 2004). It is worth noting that this ruling established a legal precedent that contrasts with the HIV criminalization policy issued by the Joint United Nations Programme on HIV/AIDS (UNAIDS), which focuses on HIV transmission and mental culpability (e.g. intent).

Further complicating the Canadian ruling, however, is that the Supreme Court failed to establish a clear threshold or test for "significant risk" in the Cuerrier case. Consequently, the lower Canadian courts have been forced to interpret the meaning of this phrase (Symington 2009). They have done so inconsistently (and inaccurately in relation to the extant scientific data on HIV transmission), both acquitting and convicting people for protected vaginal sex and for unprotected oral sex. Non-uniform rulings have 
also arisen within the lower courts in relation to the significance, meaning and interpretation of a person's viral load and its potential impact on HIV transmission. In some cases, an undetectable viral load was accepted as a valid defence, whilst in another case, a PHA's reliance on his undetectable viral load was interpreted by the judge as an attempt by the accused to shirk his disclosure responsibility; the judge in the latter case considered the PHA's use of information about viral load an exacerbating factor that resulted in maximal sentencing (JQ no 367 2011). In its totality, the result of the foregoing legal scenario in Canada regarding serostatus disclosure is a general state of confusion among lawyers, health care professionals, and PHAs about the types of sexual practices (e.g. anal, oral, vaginal) and the pertinent parameters (e.g. viral load, use of condoms or other protective devices) that determine whether or not serostatus disclosure is required (Symington 2009; Adam et al. 2008).

Lastly, to completely understand the Canadian context, a second case must also be addressed, the $R$. v. Williams case, in which the Supreme Court of Canada established that serostatus disclosure is required, not only after a positive HIV diagnosis, but also when a person has a strong suspicion that he/she could be living with HIV. Consequently, being named as a contact of HIV likely requires disclosure that one may be HIV-positive. Again, however, the Supreme Court of Canada failed to clearly articulate its rulings: They did not identify the precise degree of suspicion (the threshold of suspicion, that is) which warrants serostatus disclosure. Moreover, further ambiguity arises in this scenario because no cases have gone before any lower courts to test/refine this legal precedent; even Williams had been definitively diagnosed with HIV by the time that he was charged by the police with failing to disclosure his serostatus in situations that pose a so-called significant risk for HIV transmission.

\section{Using the Impact Fraction Model}

At this point, the literature about HIV transmission and Canadian criminal law that relates to serostatus nondisclosure will be examined using the impact fraction model. This will occur by filtering the extant literature into the model's three sections: (1) significance of target population; (2) efficacy of intervention; and (3) coverage of intervention.

\section{Significance of Target Population}

In determining the significance of a target population, one must identify, first, the target group of a specific intervention and, second, the contribution of this target group to the overall (i.e. population level) impact and scope of a specific health issue of concern. In this context, the item of interest is criminal laws which focus on HIV serostatus nondisclosure and the outcome is HIV prevention. The goal in this context is therefore to determine what public health HIV prevention effect these criminal laws might induce based on the group that these laws target. Pursuant to Canadian legal precedents, the target group comprises PHAs who are cognizant/suspicious of their serostatus. Because it is serostatus disclosure and not HIV transmission that is the issue under Canadian law, a person can only be charged for and convicted of not disclosing his/her serostatus if he/she has been diagnosed with HIV (as per the Cuerrier ruling); alternatively, these laws apply when a person is aware that he/she might be HIV-positive, e.g. is named as a contact of HIV or has regular sexual contact with a person living with HIV (as per the Williams ruling). Accordingly, based on the Supreme Court's R. v. Cuerrier and R.v. Williams rulings, the group in Canada that is targeted by criminal legal precedents which focus on serostatus nondisclosure comprises PHAs who are aware of their serostatus and individuals who are likely to be HIV-positive. Everyone else is exempt from these criminal liabilities.

Regarding the significance of the target population, the aforementioned data about HIV transmission in the Canadian context (summarized in Table 1) indicates that existing HIV disclosure laws are likely to induce small HIV prevention outcomes because they only apply to the group of PHAs who contribute $30 \%$ to $46 \%$ of the annual HIV incidence in Canada, which is somewhere between 552 $(30 \%$ of 1,840$)$ and $1,583(46 \%$ of 3,440$)$ of the 1,840 3,440 incident cases of HIV that occur by means of sexual contact each year (PHAC 2009). In other words, these laws focus on the large group of PHAs who are aware of their serostatus ( $74 \%$ of the prevalence, totalling 48,100 people; range, 39,960-56,240 individuals) and who have an HIV transmission rate that ranges between the conservative estimate of $1.15 \%$ and the liberal estimate of $3.29 \%$. These laws have no effect, by comparison, on the significantly smaller group of PHAs who are unaware of their serostatus (26\% of HIV prevalence, totalling 16,900 people; range, 14,040-19,760 individuals) and who have an estimated HIV transmission rate that varies between a low-end estimate of $5.88 \%$ (when 16,900 individuals are involved in 994 cases, or 54\%, of HIV transmission) and a high-end estimate of $14.25 \%$ (when 16,900 individuals are involved in 2,408 cases, or $70 \%$, of HIV transmission). To illustrate this point further, there are 38-93 incident cases of HIV per $1 \%$ of people unaware of their serostatus, in contrast to the 7-21 incident cases of HIV per 1\% of people aware of their serostatus. Thus, despite the group that is targeted by Canadian serostatus non-disclosure criminal precedents constituting $74 \%$ of the prevalent HIV population (which equals 48,100 people; range, 39,960-56,240), the potential prevention impact of these laws is likely small. 
This conclusion does not signify, however, that HIV prevention interventions which focus on groups that are involved in a small number of HIV transmission cases are neither effective nor important. Rather, the assertion here simply follows from the impact fraction model that greater population-level reductions in HIV transmission would like occur if HIV prevention efforts were more precisely focused on the smaller groups of people who are unaware of their positive serostatus and who are disproportionately involved in the majority of cases of HIV transmission. Such an approach would likely emphasize an increase in HIV testing among specific subpopulations who are disproportionately burdened by HIV, such as men who have sex with men, aboriginals, prison inmates and individuals of African/ Caribbean ancestry. Such an approach might help decrease delayed HIV diagnosis and may identify individuals who are in the acute HIV infection period within the groups that (1) are most profoundly affected by HIV and (2) which most profoundly affect the overall population rates of HIV incidence and prevalence.

\section{Efficacy of Intervention}

Because the Canadian courts have ruled that PHAs must disclose their serostatus prior to engaging in sexual activities that pose a "significant risk" for HIV transmission, provided that such disclosure would affect consent, it is important to review the literature that examines the relationship between HIV disclosure, the criminal law and HIV transmission. Ultimately, the impact fraction model highlights the need to determine whether an intervention, (criminal legal precedents about serostatus disclosure in this case), actually produces any HIV prevention outcomes. That is, do these laws actually induce serostatus disclosure, and do these laws change the likelihood of HIV transmission? A yes for either/both of these questions would signal that these laws could help reduce overall rates of HIV transmission; a no, by comparison, would indicate that these laws likely have little, no, or even a negative impact on HIV prevention.

As with the previous category, there is again no currently available research which specifically examines whether HIVrelated criminal laws actually promote, induce, or enhance serostatus disclosure. This is troublesome because an array of research demonstrates that many factors influence, and make it difficult to undertake, serostatus disclosure in real life, e.g. threats or experiences of violence, rejection, stigmatization, and discrimination by friends, family, peers, the general public, and health care professionals (Niccolai et al. 1999). Notwithstanding this paucity of evidence, there is one study wherein researchers examined the relationships between HIV criminal laws and people's sexual practices (Burris et al. 2007). This research involved 490 individuals (162 of which were people knowingly living with HIV) and occurred in Chicago $(n=248)$ and New York City $(n=242)$. As its outcomes, the data showed no relationships between (1) laws which proscribe certain sexual practices or require serostatus disclosure and (2) people's safer sex practices - this was the case regardless of the participant's serostatus (Burris et al. 2007). One interesting finding, nevertheless, was that the Chicago-based participants reported higher rates of unprotected sexual contact after serostatus disclosure. (More research is needed to explore this finding.) As part of this study, Burris et al. (2007) also examined whether HIVrelated criminal laws affect social norms; they questioned whether these laws change the participants' perceptions/ beliefs about serostatus disclosure? The answer that was put forward by Burris et al. (2007) was, again, that these laws have no effect. Most of the participants believed that serostatus disclosure was "morally right" and that it should occur regardless of legal obligations (Burris et al. 2007). Moral conviction about serostatus disclosure, unlike the criminal law, consistently predicted serostatus disclosure (Burris et al. 2007).

Another study by Horvath et al. (2010) validated the findings of Burris et al. (2007). In a study of 1,725 men who have sex with men over a 3.5-month period in multiple states (with and without HIV-related criminal laws), Horvath et al. (2010) found that HIV-specific criminal laws or statutes which focus on transmission and/or serostatus disclosure have no effect on the occurrence of unprotected anal intercourse. Horvath et al. (2010) thus concluded, in the same way as Burris et al. (2007), that HIV-related laws "are not a deterrent to sexual risk taking among MSM [men who have sex with men]" (p. 1226). The benefit of this second study is that it replicated and validated Burris et al.'s findings (2007), consequently mounting evidence about how inefficacious HIV-related criminal laws and statutes are as HIV prevention/public health initiatives.

A second component of determining whether criminal laws which require serostatus disclosure actually decrease the likelihood of HIV transmission is to establish the relationship between serostatus disclosure and HIV transmission. For serostatus disclosure to function as an HIV prevention strategy, it would have to induce safer sex and consequently decrease HIV transmission. Whilst the criminal law in Canada may focus on issues of consent, in this context, its relationship to and affect on HIV prevention is the point of interest and examination.

The literature on this topic (about serostatus disclosure and sexual practices, that is) produces mixed results, however. According to a recent review article, it is impossible to discern whether serostatus disclosure actually has any effect on safer sex practices and HIV transmission (Simoni and Pantalone 2004). Although some researchers found that serostatus disclosure corresponds with decreased 
HIV transmission, others found that it had absolutely no effect; other researchers, meanwhile, identified that the relationship between these two items depended on extenuating circumstances, signalling that serostatus disclosure does not consistently correspond with changes in sexual behaviour that limit HIV transmission (Simoni and Pantalone 2004). This means that whilst disclosure can affect sexual behaviour for some people in certain circumstances, many individuals who are HIV-negative knowingly engage in unprotected sex with people living with HIV. One item of importance when reviewing this material, however, is that some of these studies failed to differentiate between practices that are likely/unlikely to transmit HIV (e.g. oral vs. protected vaginal/anal vs. unprotected vaginal/anal sex). It could be, quite simply, that sexual contacts still occurred in many cases, but in ways that prevent HIV transmission.

To explain these studies, first, among their 255 multiethnic men living with HIV in Los Angeles, De Rosa and Marks (1998) found that protected sexual contact occurred more commonly after serostatus disclosure. Similarly, among 609 men of various ethnicities living with HIV in Los Angeles, Marks et al. (1994) found people living with HIV a slight increase in the frequency of unprotected insertive anal sex after serostatus disclosure than when serostatus disclosure did not occur, 18\% and $23 \%$ respectively. Sturdevant et al. (2001) produced corresponding results with a group of 153 sexually active adolescent girls living with HIV, wherein less condom use was reported when serostatus disclosure did not occur. In contrast, however, Crepaz and Marks (2003) identified that there was no identifiable relationship between serostatus disclosure and safer sex in their research sample of 105 men who are living with HIV in Los Angeles. Marks and Crepaz (2001) had previously found similar results: Among 206 men of various ethnicities living with HIV in Los Angeles, the occurrence of unsafe sex was identical regardless of whether serostatus disclosure occurred or not. Likewise, among 269 men and women who are living with HIV, Kalichman et al. (2002) found that regardless of serostatus disclosure, protected sex occurred at the same frequency with both regular and non-regular partners. D'Angelo et al. (2001) had previously produced the same results with 203 male and female adolescents living with HIV. Ultimately, these results highlight that serostatus disclosure should not be considered an efficacious HIV prevention strategy.

\section{Coverage of Intervention}

The third aspect of the impact fraction model focuses on coverage, which relates to the number of people within a specific group of interest (i.e. the target population) whom an intervention addresses and the proportion of these individuals for whom the intervention can be or is actualized in a way that promotes desired outcomes (e.g. health promotion or illness prevention). Coverage, as it is used in this context, therefore describes the extent of an intervention's applicability, uptake, or use by the members of a specific community, not its uptake, use, or application within the general population. Herein, examinations of coverage query how many PHAs who know their serostatus are aware of their local HIV-related criminal laws which mandate serostatus disclosure.

To answer this question, a few sources of information can be drawn from. The first is an empirical study by Galletly et al. (2009) which sought to determine the proportion of diagnosed PHAs who were aware of their jurisdictional serostatus disclosure laws in one unidentified US state. This study involved 384 PHAs, of which $63.9 \%$ were male, 54.3\% black and 54.3\% men who had sex with both men and women. The findings of this study revealed that most participants (76\%) were aware of relevant laws, but that $19.3 \%$ of the study sample were nevertheless unaware whether serostatus disclosure laws existed, and $4.7 \%$ believed that no such laws existed in their state. Based on these findings, Galletly et al. (2009) concluded that comprehension of these laws was "generally good" within their study sample and that this was likely due to diagnosed PHAs receiving information about these laws from a variety of sources: HIV support groups, AIDS service organizations, health care professionals, public health departments, general media, and so forth (p. 1265). As indicated by this study, coverage, if measured in relation to knowledge about HIV disclosure laws, appears to be high.

A qualitative study by Adam et al. (2008), meanwhile, explored in greater detail the interpretation and meaning of serostatus disclosure laws for 34 men living with HIV in Canada (Toronto, Ontario, specifically). The results of this study identified "ambiguity and uncertainty" among the participants regarding the meaning and significance of Canadian serostatus disclosure laws in real-life (p. 159). Thus, whilst the participants appeared to be generally aware of the R. v. Cuerrier precedent, they were neither in agreement about whether it was beneficial nor were they clearly able to surmount some of the "practical dilemmas" which are associated with this criminal law (p.160). This second study, when considered in hand with the findings of Galletly et al. (2009), suggests that although survey-based data collection about serostatus disclosure laws reveal a high degree of awareness, in-depth qualitative-based discussions highlight many shortcomings in PHAs' actual understandings of these laws, e.g. what they mean in and as part of real life, day-to-day sexual interactions and personto-person communication. Nevertheless, both studies did demonstrate a relatively high degree of coverage: Most 
participants were aware of local laws which mandate serostatus disclosure in particular situations.

\section{Discussion}

When the Canadian criminal legal precedents that require serostatus disclosure (R. v. Cuerrier and R. v. Williams) are examined using the impact fraction model, it appears as though the public health and HIV prevention effects of these rulings would likely be limited. Indeed, whilst enforcement of serostatus disclosure by means of criminal law might affect transmission in a small number of cases (although Cameron 2009 argues that such an assertion is debatable), the overall population-level HIV prevention impact of these laws would probably be quite limited. This is particularly the case when these HIV prevention effects are compared with the prevention impact that could arise if interventions were focused in other subpopulations, such as among the individuals in sexual networks with high HIV incidence and prevalence who are unaware of being HIVpositive. This conclusion is well founded because, regarding the impact fraction model, Canadian serostatus disclosure laws have two shortcomings that limit their success.

First, extant serostatus non-disclosure law focuses on the people living with HIV who are likely involved in the minority of HIV transmission in Canada; PHAs who are aware of their serostatus are likely involved in 30\% to $46 \%$ of new cases of HIV. In contrast, PHAs who are unaware of their serostatus are likely involved in $54 \%$ to $70 \%$ of ongoing HIV transmission. As this relates to HIV prevention, it is distinctly possible that a more profound HIV prevention effect could arise if the smaller group of PHAs who are unaware of their serostatus, but who are involved in the majority of HIV transmission, were identified as the priority group for HIV prevention. (As noted above, within the Canadian context, this would mean that HIV prevention efforts should focus on men who have sex with men, aboriginal groups, prison inmates and individuals of African/Caribbean ancestry, to name a few groups of importance.) As the second main shortcoming, the potential prevention effects of Canadian criminal precedents about serostatus disclosure are likely limited because the available evidence refutes the idea that these rulings induce behaviours that decrease HIV transmission; this is the case regarding both the relationships between these rulings and serostatus disclosure and the correlation between serostatus disclosure and safer sex practices. Using the language of the impact fraction model, serostatus disclosure thus appears to be an inefficacious HIV prevention strategy.

Compounding the fact that serostatus non-disclosure criminal law likely has a small HIV prevention effect is that other authors suggest that these legal precedents might consequently decrease HIV testing among PHAs who are unaware of their serostatus (Cameron 2009; Symington 2009; UNAIDS 2002; Galletly and Pinkerton 2006; Bennett et al. 2000; Lazzarini et al. 2002; Wolf and Vezina 2004). Because this group of PHAs is disproportionately implicated in continued HIV transmission, and because the impact fraction model suggests that the proportional significance of this group makes it is a priority population for HIV prevention, a reduction in HIV testing, serostatus awareness and the HIV prevention outcomes that often correspond with serostatus awareness (e.g. viral load suppression, behaviour change, partner notification and follow-up by public health departments) could in fact exacerbate population-level rates of HIV transmission. That is, HIV transmission could worsen if people purposively chose to decrease their criminal liability and remain unaware of their serostatus. The logic behind this argument is simple: Laws which target PHAs who are aware of their serostatus may deter PHAs who are unaware of their serostatus from wanting to undergo HIV testing. As it stands in Canada, a person can only be charged with a serostatus non-disclosure if he/she knows or is strongly suspicious about his/her serostatus (whether this knowledge arises from a definite test or from being named as a contact of HIV by a health professional). Ignorance of one's serostatus (including ignorance of the possibility that one could be HIV-positive) is therefore a form of immunity to the Cuerrier and Williams precedents.

This incentive to be and to remain unaware of one's serostatus, however, conflicts with research findings which indicate that knowing one's serostatus corresponds with decreased HIV transmission. This outcome also conflicts with HIV prevention messaging issued by the World Health Organization (WHO 2007), the Public Health Agency of Canada PHAC (2006) and CDC (2009) - all three of whom have highlighted the importance of removing any/all barriers that inhibit HIV testing. In the USA, specifically, the CDC (2009) has even gone so far as to endorse the idea of opt-out testing (wherein an HIV test is the norm unless otherwise stated by the patient) in an effort to minimize the number of people who are unaware of their serostatus. However, if individuals wish to protect themselves from serostatus nondisclosure legal precedents, and if they refrain from accessing HIV testing consequently, then the already limited HIV prevention effect of the serostatus non-disclosure rulings would be further diminished. To explain this scenario further: If the number of individuals who are unaware of being HIVpositive were to increase as a consequence of these criminal prosecutions, then the outcome could be a situation of increased HIV transmission as a result of a larger number of people being unaware of their serostatus.

Ironically, however, no researchers have examined whether HIV criminal laws actually affect the uptake and 
use of HIV testing services by different subpopulations of interest. Consequently, the only data that can inform discussions on this topic arise from other research studies which examine the array of factors that deter individuals from accessing HIV testing services (see, for example, Malta et al. 2007; Hogben et al. 2004; Maher et al. 2000). Based on the foregoing list of research studies, which identifies limitations of confidentiality, social stigmatization/discrimination and fears of violence as the most common non-monetary items that dissuade people from undergoing HIV testing, it is not an unreasonable to postulate that the criminal prosecution of serostatus nondisclosure might also deter HIV testing. Public prosecutions and the ensuring media coverage of these trials efface confidentiality, whilst such criminal proceedings also likely exacerbate HIV stigmatization and discrimination. Within the present state of affairs, however, one can only speculate that the criminal law system might deter testing because there are no empirical studies which substantiate these conclusions. This lack of evidence however, does not mean that such assertions are not true; rather, it signals a need for in-depth research on this topic.

Moving beyond the potential HIV prevention impact of serostatus non-disclosure criminal laws, another problem with contemporary Canadian laws is that they do not encourage what Marks and Crepaz (2001) call "uninformed protection", which involves PHAs who are aware of their serostatus (1) intentionally engaging in safer sex practices in an effort to minimize HIV transmission (e.g. when a person living with HIV eschews unprotected vaginal and/or anal sex in favour of exclusive oral sexual contact) (2) but doing so without disclosing their serostatus. Because the current Canadian legal precedents address serostatus disclosure, they focus on serostatus awareness not decreasing HIV transmission. The outcome is that, as per the $R$. v. Cuerrier and $R$. v. Williams ruling, the Canadian criminal system equally punishes PHAs who take all precautions to, and successfully prevent HIV transmission, and other PHAs who intentionally wish to and effectively do transmit HIV to other people. It is quite plausible, therefore, that this legal situation does not encourage PHAs who refrain from disclosing their serostatus for whatever reasons to attempt to minimize HIV transmission in situations wherein serostatus disclosure did not/does not occur. Indeed, without disclosure, the criminal act has already been committed.

As a final point, it is important to note that the criminal law system is not inherently opposed to HIV prevention. Rather, it is simply that at a broad level, the criminalization of serostatus non-disclosure might not create a social context that facilitates safer sex, serostatus awareness and HIV prevention efforts. When, for example, a PHA who is aware of his/her status is forced to chose between the possibility of future criminal proceedings and the immediate potential for violence or rejection or humiliation, one is forced to question not just the magnitude of the HIV prevention impact that such criminal law could induce but also whether or not the criminal law system actually has any potential to prevent HIV transmission. Moreover, when the WHO, the Centers for Disease Control and Prevention (CDC) and the Public Health Agency of Canada (PHAC) endorse the idea of increased serostatus awareness by means of increased HIV testing, one must wonder whether an acceleration in criminal prosecutions for serostatus non-disclosure, as is occurring in Canada, actually supports a society of serostatus awareness and disclosure, of decreased HIV-related stigmatization and discrimination and of HIV prevention. The point here is that whilst the criminal law punishes individuals who have engaged in proscribed actions, it does not appear to function synergistically within the social reality and public/public health policy environment that surrounds HIV transmission, HIV prevention and serostatus disclosure. Indeed, it appears as though the criminal law system offers little promise to do anything other than exacerbate HIV transmission within the Canadian context.

\section{Conclusion}

Reflections on the topic of HIV serostatus non-disclosure and the criminal law that are guided by the impact fraction model emphasize that even if these laws were to prevent HIV transmission (which appears to be unlikely), the potential public health prevention impact of HIV disclosure laws is not optimal because more substantial prevention outcomes could occur if strategic public health policy efforts were directed toward decreasing transmission within the smaller but more fractionally important population of PHAs who are unaware of their serostatus. Following the impact fraction model, which indicates that interventions likely have a greater effect when they target smaller groups of individuals who are disproportionately responsible for a health issue, HIV disclosure laws do not target the group that is most significant from a transmission and prevention perspective. The criminal enforcement of serostatus disclosure thus does not appear to be an ideal prevention strategy because it would not likely induce much of an overall population-level HIV prevention effect. Furthermore, this approach also holds the potential to induce other unwanted consequences that might impede HIV prevention, such as the encouragement of serostatus ignorance, the exacerbation of HIV-related stigmatization and discrimination and/or the reduction of safer sex in situations of serostatus non-disclosure.

Consequently, when selecting between various policy options regarding HIV prevention, it is suggested as a result of this analysis that resources which might be devoted to the criminal law system for HIV serostatus non-disclosure 
prosecutions could be better invested elsewhere. As per the stipulations and insights of the impact fraction model, HIV prevention efforts should focus on the groups which are disproportionately burdened by HIV, which account for the largest number of people who are unaware that they are living with HIV and which have the highest rates of HIV transmission; it is within these groups that the greatest improvements in public health will occur. Accordingly, HIV prevention workers, and anyone else who is also involved in making decisions that could impact on HIV prevention for that matter, should be cognizant that applying the harsh hand of the criminal law to a subset of individuals who are already burdened by HIV and its associated physical, social and inter/intrapersonal consequences could likely both (1) produce insignificant HIV prevention outcomes and (2) induce secondary outcomes that might exacerbate HIV transmission at the population level.

Open Access This article is distributed under the terms of the Creative Commons Attribution Noncommercial License which permits any noncommercial use, distribution, and reproduction in any medium, provided the original author(s) and source are credited.

\section{References}

Adam, B. D., Elliott, R., Husbands, W., Murray, J., \& Maxwell, J. (2008). Effects of the criminalization of HIV in Cuerrier on men reporting unprotected sex with men. Canadian Journal of Law and Society, 23(1-2), 143-159.

Aral, S. O., Lipshutz, J. A., \& Douglas, J. M. (2007). Introduction. In S. O. Aral, J. A. Lipshutz, \& J. M. Douglas (Eds.), Behavioural interventions for prevention and control of sexually transmitted diseases (pp. 9-19). New York: Springer Science.

Bennett, R., Draper, H., \& Frith, L. (2000). Ignorance is bliss? HIV and moral duties and legal duties to forewarn. Journal of Medical Ethics, 26, 9-15.

Burris, S., Beletsky, L., Burleson, J., Case, P., \& Lazzarini. (2007). Do criminal laws influence HIV risk behaviour? An empirical trial. Arizona State Law Journal, 39, 467-519.

Canadian HIV/AIDS Legal Network. (2004). Disclosure of HIV status after Cuerrier: Resources for community based AIDS organizations. Retrieved from http://www.aidslaw.ca/publications/ publicationsdocEN.php?ref536.

Cameron, E. (2009). Criminalization of HIV transmission: Poor public health policy. HIV/AIDS Policy \& Law Review, 14(2), 62-75.

CDC (Centers for Disease Control and Prevention). (2009). HIV testing. Accessed 13 April 2011 from http://www.cdc.gov/hiv/ topics/testing/index.htm.

Crepaz, N., \& Marks, G. (2003). Serostatus disclosure, sexual communication and safer sex in HIV-positive men. AIDS Care, $15,379-387$.

D’Angelo, L. J., Abdalian, S. E., Sarr, M., Hoffman, N., Belzer, M., \& Adolescent Medicine HIV/AIDS Research Network. (2001). Disclosure of serostatus by HIV infected youth: the experience of the REACH study. Reaching for Excellence in Adolescent Care and Health. Journal of Adolescent Health, 29(Suppl 3), 72 79.

De Rosa, C. J., \& Marks, G. (1998). Preventive counseling of HIVpositive men and self-disclosure of serostatus to sex partners: new opportunities for prevention. Health Psychology, 17, 224-231.
Dooley, S. W., \& Thrun, M. (2008). HIV transmission prevention in the context of care. In K. K. Holmes et al. (Eds.), Sexually transmitted diseases (4th ed., pp. 1363-1392). New York: McGraw-Hill.

Galletly, C. L., \& Pinkerton, S. D. (2006). Conflicting messages: How criminal HIV disclosure laws undermine public health efforts to control the spread of HIV. AIDS \& Behaviour, 10, 451-461.

Galletly, C. L., \& Pinkerton, S. D. (2008). Prevention HIV transmission via HIV exposure laws: Applying logic and mathematical modelling to compare statutory approaches to penalizing undisclosed exposure to HIV. The Journal of Law, Medicine \& Ethics, 36(3), 577-584.

Galletly, C. L., DiFranceisco, W., \& Pinkerton, S. D. (2009). HIVpositive persons' awareness and understanding of their state's criminal HIV disclosure laws. AIDS Behaviour, 13, 12621269.

Hall, H. I., Geduld, J., Boulos, D., Rhodes, P., An, Q., Mastro, T. D., et al. (2009). Epidemiology of HIV in the United States and Canada: Current status and ongoing challenges. Journal of Acquired Immune Deficiency Syndromes, 51, s13-s20.

Hogben, M., Bloom, F., MacFarlane, M., St. Lawrence, J., Malotte, K., \& The GCAP Study Group. (2004). Factors associated with sexually transmitted disease clinic attendance. International Journal of Nursing Studies, 41, 911-920.

Horvath, K. J., Weinmeyer, R., \& Rosser, S. (2010). Should it be illegal for HIV-positive persons to have unprotected sex without disclosure? An examination of attitudes among US men who have sex with men and the impact of state law. AIDS Care, 22 (10), 1221-1228.

Kalichman, S. C., Rompa, D., Luke, W., \& Austin, J. (2002). HIV transmission risk behaviours among HIV-positive persons in serodiscordant relationships. International Journal of STDs and AIDS, 13, 677-682.

Lazzarini, Z., Bray, S., \& Burris, S. (2002). Evaluating the impact of criminal laws on HIV risk behaviour. The Journal of Law, Medicine \& Ethics, 30(2), 239-253.

Maher, J. E., et al. (2000). Partner violence, partner notification, and women's decisions to have an HIV test. JAIDS, 25, 276-282.

Malta, M., et al. (2007). Knowledge, perceived stigma, and careseeking experiences for sexually transmitted infections: A qualitative study from the perspective of public clinic attendees in Rio de Janeiro, Brazil. BMC Public Health, 7, 18. doi:2007.

Marks, G., \& Crepaz, N. (2001). HIV-positive men's sexual practices in the context of self-disclosure of HIV status. Journal of Acquired Immune Deficiency Syndromes, 27, 79-85.

Marks, G., Ruiz, M. S., Richardson, J. L., Reed, D., Mason H. R. C., Sotelo, M., \& Turner, P. A. (1994). Anal intercourse and disclosure of HIV infection among seropositive gay and bisexual men. Journal of Acquired Immune Deficiency Syndromes, 7(8), 866-886.

Marks, G., Crepaz, N., Senterfitt, J. W., \& Janssen, R. S. (2005). Meta-analysis of high-risk sexual behaviour in persons aware and unaware they are infected with HIV in the United States. Epidemiology and Social Science, 39(4), 446-453.

Myhkalovskiy, E., Betteridge, G., \& McLay, D. (2010). HIV nondisclosure and the criminal law: Establishing policy options for Ontario. Accessed 10 November 2010 from www.catie.ca/pdf/ Brochures/HIV-non-disclosure-criminal-law.pdf.

Niccolai, L. M., Dorst, D., Meyers, L., \& Kissinger, P. J. (1999). Disclosure of HIV status to sexual partners: Predictors and temporal patters. Sexually Transmitted Diseases, 26, 281-285.

PHAC (Public Health Agency of Canada). (2006). HIV testing and counselling: Policies in transition? Ottawa: Government of Canada. 
PHAC (Public Health Agency of Canada). (2009). Estimates of HIV prevalence and incidence in Canada, 2008. Ottawa: Government of Canada.

Simoni, J., \& Pantalone, D. (2004) Secrets and safety in the age of aids: does HIV disclosure lead to safer sex? Topics in HIV Medicine, 12(4), 109-118.

Sturdevant, M. S., Belzer, M., Weissman, G., Friedman, L. B., Muenz, L. R., \& Adolescent Medicine HIV/AIDS Research Network. (2001). The relationship of unsafe sexual behavior and the characteristics of sexual partners of HIV infected and HIV uninfected adolescent females. Journal of Adolescent Health, 29(Suppl 3), 64-71.
Symington, A. (2009). Criminalization confusion and concerns: The decade since the Cuerrier decision. HIV/AIDS Policy \& Law Review, 14(1), 4-10.

UNAIDS. (2002). Criminal Law, Public Health and HIV Transmission: A Policy Options Paper. Geneva: UNAIDS.

Wolf, L. E., \& Vezina, R. (2004). Crime and punishment: Is there a role for criminal law in HIV prevention policy? Whittier Law Review, 821(25), 1-59.

WHO (World Health Organization). (2007). Guidance on providerinitiated HIV testing and counselling in health facilities. Accessed 11 April 2011 from http://whqlibdoc.who.int/publica tions/2007/9789241595568_eng.pdf. 